\title{
Assessment of Application Technology of Natural User Interfaces in the Creation of a Virtual Chemical Laboratory
}

\author{
Piotr Jagodziński • Robert Wolski
}

Published online: 24 September 2014

(c) The Author(s) 2014. This article is published with open access at Springerlink.com

\begin{abstract}
Natural User Interfaces (NUI) are now widely used in electronic devices such as smartphones, tablets and gaming consoles. We have tried to apply this technology in the teaching of chemistry in middle school and high school. A virtual chemical laboratory was developed in which students can simulate the performance of laboratory activities similar to those that they perform in a real laboratory. Kinect sensor was used for the detection and analysis of the student's hand movements, which is an example of NUI. The studies conducted found the effectiveness of educational virtual laboratory. The extent to which the use of a teaching aid increased the students' progress in learning chemistry was examined. The results indicate that the use of NUI creates opportunities to both enhance and improve the quality of the chemistry education. Working in a virtual laboratory using the Kinect interface results in greater emotional involvement and an increased sense of self-efficacy in the laboratory work among students. As a consequence, students are getting higher marks and are more interested in the subject of chemistry.
\end{abstract}

Keywords Human-computer interfaces · Improving classroom teaching - Interactive learning environments . Simulations · Virtual reality

\section{Introduction}

The natural sciences such as chemistry, physics, biology or experiments conducted in a laboratory or in outdoor

\footnotetext{
P. Jagodziński · R. Wolski $(\bowtie)$

Faculty of Chemistry, Department of Chemical Education, Adam

Mickiewicz University, Umultowska 89b, 61-614 Poznań,

Polska

e-mail:wola@amu.edu.pl
}

activities are of great importance. In this respect, the science of chemistry poses special experimental opportunities to engage senses of the experimenter to determine the physical and chemical properties of the substance. There is advantageous situation in the chemical education, when students can perform individually most of the chemical experiments covered by the curriculum, (Lagowski 1998). In this case, the work of students in the laboratory has a positive effect on the process of teaching and learning (Leite and Afonso 2002), in which laboratory environment plays a very important role. Teachers of science confirm that the active work of students in the laboratory provides measurable benefits in teaching (Hofstein and Lunetta 1982). Also, educators claim that the teaching of chemistry, which is the Natural Science subject, is most effective when students work in the laboratory having direct contact with matter being converted (Tezcan and Bilgin 2004). The idea of working in the laboratory is based on the thesis that students should perform in the laboratory especially those experiments, which are carriers of basic information in a particular scientific discipline. This is particularly valuable from the point of view that equipment and working methods of pupils during the execution of the experiments in chemical laboratory are elements of individual work, through which each student independently can train basic skills, for example, with the techniques of laboratory work (Tatli 2009). In addition, the laboratory exercises, which are a form of realization of practical teaching methods and the associated intellectual activity of students, such as reasoning, critical thinking and scientific prediction cause an increase in theoretical and laboratory-based problemsolving skills (Odubunni and Balagun 1991; Ayas et al. 1994). With the acquired skills, students are motivated to independent, critical thinking and the design of experiments and research in a way in which scientists do. At the 
end of the thesis, it is very important that understanding what is real is only effective when it binds to its transformation (Bozdogan and Yalcin 2004). Currently, the teaching of science is based on the education of students whose major elements are the analysis of the processes leading to specific scientific knowledge and the ability to apply that knowledge. This way of teaching generates an increase in problem-solving skills among students (Yang and Heh 2007). Building scientific knowledge of students is associated with their ability of analytical thinking, which includes scientific reasoning and critical thinking (Roth and RoyChoudhury 1993; Tamir and Lunetta 1981). Scientific inquiry just as logical thinking requires student engagement (Roschelle et al. 2000), the understanding of scientific knowledge and processes that are dependent on the cognitive structure related to the scientific, intellectual and social context (Cobb and Bowers 1999; Calik and Coll 2012; Calik et al. 2013). A constructivist model of learning suggests that knowledge is the result of the interaction of individual actions or activities by which this model of learning is crucial to the active participation of students (Bernard et al. 2004). The point here is that the student should construct or actively create their knowledge through thinking and practical action (Tatli and Ayas 2012).

Today, we are witnessing the rapid development of information and communication technologies (ICT). This development has a large impact on teaching, education and the process of teaching and learning (Xie and Reider 2013). A major problem is the proper integration and implementation of this technology into the educational process in such a way as to be able to assist students in developing their knowledge and skills (Zhang 2013). You can highlight five areas in which different features and capabilities of ICT are used: scientific texts and lectures, cooperation and scientific discussion; representation and data collection, scientific simulation, and, finally, modeling (Linn 2003). Depending on the context of the use of ICT technology, these various expressions are used: information technology (Xie and Reider 2013), information and communication technology (Linn 2003), technology of learning (Atwater 2000; Krajcik 2002), new technologies (Krajcik et al. 2000) and innovative technologies (Calik 2013; Ebenezer et al. 2011, 2012; Xie and Reider 2013). ICT technology, regardless of the name, may help students and teachers to broaden their thinking horizons, better mutual communication of one another, a better understanding of scientific phenomena and conducting investigations to carry scientific research (Edelson 1998; Krajcik 2002; Zhang 2013). It follows that ICT tools can be useful to students in inquiring and further understanding of scientific concepts (Krajcik 2002). One of the ways to use ICT in education can be the Serious Games. Working with Serious Games directly engages students to act resulting in the absorption of information, without the involvement of third parties as opposed to learning in the classroom where the teacher passes information on to students (Chee and Tan 2012). The advantage of Serious Games is that the student can work with them at home to repeat the knowledge acquired in the classroom in school or while preparing for a new classes (De Grove et al. 2012). Serious Games can also serve as a primary source of information for students. They can also contribute to the growth of problem-solving skills by students and can shape the ability to work in a group (Sánchez and Olivares 2011).

One of the types of computer educational games can be a virtual laboratory. Virtual laboratories allow the free operation of learning in any place and at any time. They can help to relieve the education of the walls of the school and move it to a different part of the environment, enhancing the dynamic of learning with the use of simulations (Yang and Heh 2007; De Grove et al. 2012). In the virtual laboratories, students demonstrated an active part in the performance of experiments, working alone or in collaboration with colleagues. In this case, the ability to simulate different activities significantly differentiates virtual laboratories from traditional computer applications (Dede et al. 1996). Furthermore, thanks to the flexibility of virtual laboratories, abstract concepts found in chemistry become more understandable. Students using virtual laboratories can work according to their pace of learning and personal needs (Sanger 2000; Stieff and Wilensky 2003; Pekdag 2010). In the traditional laboratory, work involves technical problems, absolute compliance with safety regulations, costs associated with equipment and performing experiments and reduction of hours devoted to laboratory work. One of the effective solutions to these problems is currently available virtual laboratories, which to some extent allow for experimentation without the above restrictions (Millar 2004; Bilek 2010). Working with them lies in the proper use of the computer using the keyboard or mouse as input interfaces ("Chemistry Lab" n.d.). The appearance of the NUI has created new opportunities in the control of simulation programs. The control is done using the natural movements and gestures of the user making the service more natural and intuitive. Accordingly, it is possible to prepare a software which enables the user to be more engaged in practical activities (Svec and Anderson 1995).

We conclude that described in the literature virtual laboratories are based on interfaces such as a keyboard and mouse. They do not provide a support for the natural behavior of the program's user that is experienced when working in a real laboratory. To eliminate these limitations and make students work in a virtual laboratory more like the work in a real laboratory, a virtual chemical laboratory was prepared, which uses NUI. In this case, the interface 
was used, wherein the sensor is Kinect. Thanks to this sensor, the prepared program allows a proper analysis of hand movements, allowing natural gestures while performing chemical experiments. So far, the developed virtual laboratory simulations of chemical operations are carried out using traditional interfaces such as mouse and keyboard. In contrast, the use of NUI creates new opportunities in the design of virtual laboratories. For this reason, research is needed on the usefulness of virtual laboratories with NUI.

Such studies were performed, using a virtual laboratory for teaching chemistry in the Junior and Senior High Schools. The results were supposed to answer the questions, which were of interest to us:

- We wanted to check what the educational effectiveness of a virtual laboratory in teaching chemistry;

- we wanted to determine how work in a virtual laboratory affects the subsequent involvement of the students working in a real laboratory;

- we wanted to determine how the work of students in the virtual laboratory affects the change in self-efficacy while working in a real laboratory;

- we wanted to determine which of the three prepared versions of a virtual laboratory is most suitable for students in their work.

\section{Technical aspects of program preparation}

\section{What is NUI}

Natural User Interfaces are types of interfaces, which provide the ability to communicate with various devices in a natural way for human beings. NUI task is to create interaction between the man and the machine in such a way that the user is not aware of the existence of the interface. NUI can work in many different ways, depending on your needs and requirements. A commonly used Natural User Interface is a touch screen interface which allows you to move and manipulate objects through touch and drag your fingers across the screen. In this case, the objects on the screen, similarly to real objects, may respond to the touch. This feedback through touch interface makes controlling devices or applications seem more natural than those using a keyboard and mouse. While using a smartphone or a tablet, most users are unaware of the fact that the interaction is mediated by the touch interface ("Natural User Interface" 2011; Murphy 2012).

An interesting type of NUI, attractive to us, is gesture recognition and movement tracking systems, which in turn are translated by the interface on the instructions understood by the computer. The work of some of these interfaces as the Nintendo Wii ("Controls for Wii" n.d.) or PlayStation Move ("This Is How I Move" n.d.) is based on accelerometers and gyroscopes tracking roll angle, speed and acceleration. A more intuitive kind of NUI is equipped with a camera and internal software (firmware) on your device that recognizes specific gestures and translates them into appropriate action. Microsoft Kinect ("Kinect for Windows" n.d.), or LEAP Motion ("LEAP Motion" n.d.; Kosner 2012), allows users to interact through body movements, gestures and voice commands. In addition to these popular, there are other interfaces that are based on voice recognition, eye movement or brain wave analysis ("Natural User Interface" 2011).

The technology used for the preparation of the program

To prepare a program that simulates school chemistry laboratory, available information technology (ICT) was used. First of all, the Kinect for Windows SDK package was used allowing support for Kinect from Windows. This package offers a number of tools, formulas and functions, in order to facilitate developers the ability to create and improve applications responding to human gestures and voice. This package contains the necessary drivers to connect Kinect to a Windows PC ("Skeletal Tracking" n.d.). The software of the school chemistry laboratory is written in C\#. In addition, development work benefited from part of the package .NET, known as Windows Presentation Foundation (WPF), that allows you to prepare a graphical user interface. This package is also responsible for on-screen display the developed graphical user interface ("Windows Presentation Foundation" n.d.). It uses the universal language of XML tags designed to represent different data in an orderly manner ("XAML Overview" n.d.). In our case, this language was used to describe the laboratory equipment, chemicals, instructions to experiments and interactions taking place.

To detect and analyze user movement, the prepared software uses sensor Kinect for Windows. This sensor has a higher technical capabilities such as higher resolution scan of the form and possible shorter the distance the user from the sensor than the Kinect for XBOX intended ("Kinect for Windows" n.d.).

The description of the school's simulating chemical laboratory

The program that simulates a school chemistry laboratory enables full recreation of the activities performed during the experiment. You can simulate grasping laboratory glass and equipment and appropriate mounting them. Also, a 
simulation of pouring solid substances, liquids and solutions into laboratory glassware, and other laboratory activities were designed. The program takes into account the correct simulation of liquids movements during their transfer or during a chemical reaction and the correct simulation of the movement of solid particles during their collection and pouring into the laboratory dishes. The program allows performing 40 chemical experiments, which are valid in the chemistry curriculum in Junior and Senior High Schools in Poland. One can simulates such experiments as: the comparison of the chemical reactivity of metals, carbon dioxide characterization, synthesis of hydrochloric acid by dissolution of hydrogen chloride in water, study of the effect of temperature on the solubility of gases in water, the effect of temperature on the rate of chemical reaction, testing the reactivity of hydroxides and acids on oxides. The program uses a system that monitors the performance of laboratory activities by which the actions inappropriate or contrary to the principles of safe work in the chemical laboratory are indicated to the user and blocked. The purpose of this is to familiarize the user with rules of proper and safe work in the laboratory (Fig. 1).

In order to conduct research on the effectiveness of the Kinect using program in the simulating school chemical laboratory in the teaching of chemistry, three program versions were prepared. In the first version, the student

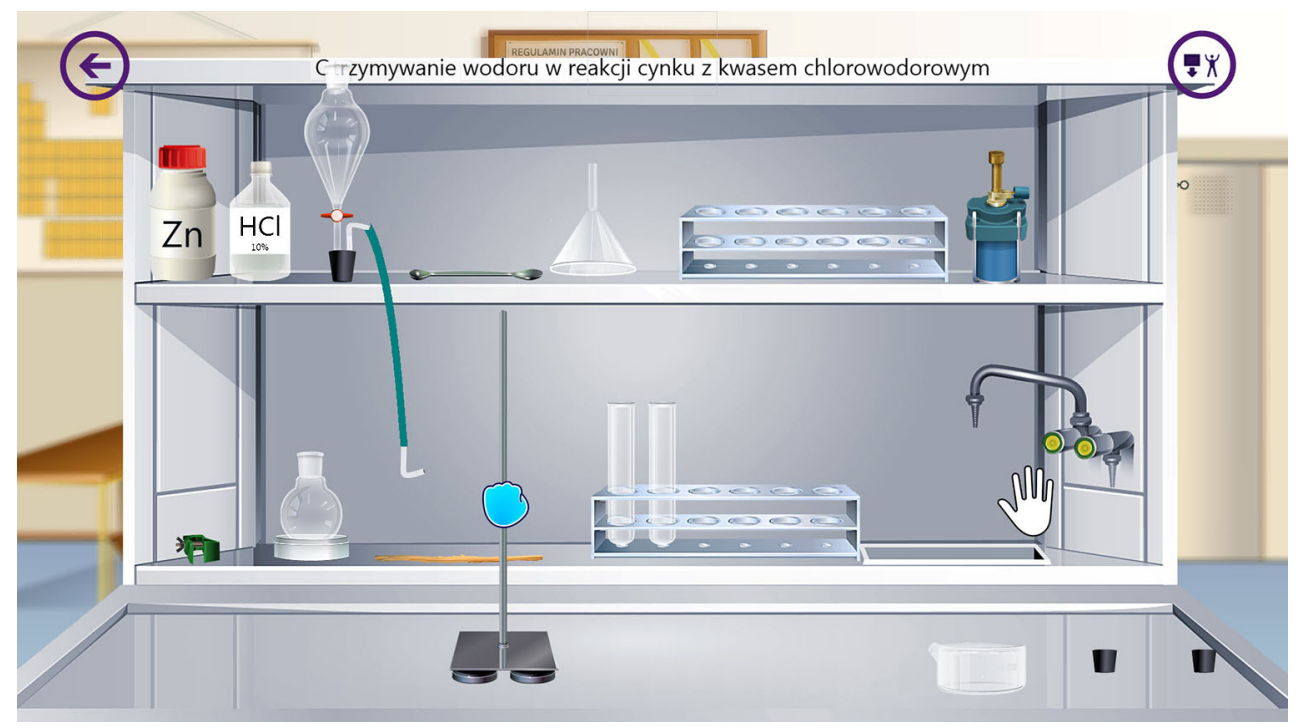

Fig. 1 Screenshot from the simulation software shows general view of the virtual laboratory

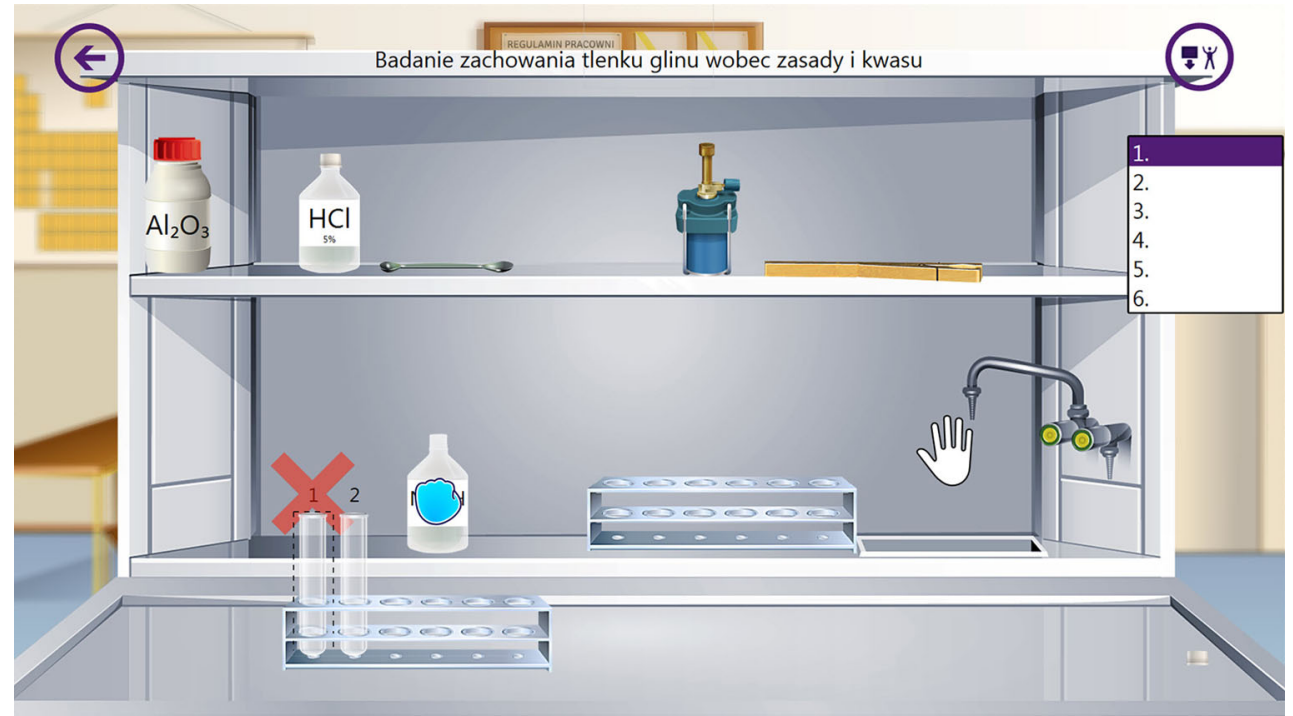

Fig. 2 Screenshot shows incorrect laboratory procedure 
Table 1 Designation of particular groups of students, depending on the measure

\begin{tabular}{|c|c|c|c|c|}
\hline $\begin{array}{l}\text { Designation of } \\
\text { groups of } \\
\text { students }\end{array}$ & $\begin{array}{l}\text { The description of the teaching aid } \\
\text { which Junior High School students } \\
\text { worked with }\end{array}$ & $\begin{array}{l}\text { The number } \\
\text { of students } \\
{[\mathrm{n}]^{*}}\end{array}$ & $\begin{array}{l}\text { The number } \\
\text { of schoolboys } \\
\text { [f] }\end{array}$ & $\begin{array}{l}\text { The number } \\
\text { of schoolgirls } \\
\text { [m] }\end{array}$ \\
\hline GKL & $\begin{array}{l}\text { Virtual laboratory with commands } \\
\text { from teacher }\end{array}$ & 25 & 12 & 13 \\
\hline GKF & $\begin{array}{l}\text { Virtual laboratory with instructional } \\
\text { films }\end{array}$ & 25 & 14 & 11 \\
\hline GKT & Virtual laboratory with instruction texts & 25 & 14 & 11 \\
\hline GTF & $\begin{array}{l}\text { Instruction texts and instructional films } \\
\text { without virtual laboratory }\end{array}$ & 25 & 10 & 15 \\
\hline \multicolumn{5}{|c|}{ The description of the teaching aid which Senior High School students worked with } \\
\hline LKL & $\begin{array}{l}\text { Virtual laboratory with commands } \\
\text { from teacher }\end{array}$ & 25 & 12 & 13 \\
\hline LKF & Virtual laboratory with instructional films & 25 & 14 & 11 \\
\hline LKT & Virtual laboratory with instruction texts & 25 & 13 & 12 \\
\hline LTF & $\begin{array}{l}\text { Instruction texts and instructional films } \\
\text { without virtual lab }\end{array}$ & 25 & 14 & 11 \\
\hline
\end{tabular}

performs various laboratory activities in accordance with the instructions given by the teacher. In the second version of the program, teacher's instructions were replaced by the video with a recorded course of experiments. These videos are multimedia instructions, by means of which the student experiences the virtual reality. In the third version, the student displays on the screen the text of the conventional instructions to experiments. The student after familiarizing with the content performs a simulation of the experiment. Both video and conventional instructions are available in the program at the request of the student during the execution of simulated experiments. All three versions of the program indicate when a student makes a mistake in the laboratory work (Fig. 2).

\section{Description of research methodology}

\section{Description of groups of students}

The 3 year Junior High School and the 3 year Senior High School terms apply to the Polish educational system. Four Junior High School and four Senior High School classes took part in this pedagogical research. The study included second year students of both types of schools, because in this period the subject of chemistry is realized in the greatest number of hours. In particular school, each class was a separate research group of students. The choice of classes in each group was random. Second-grade Junior High School students were 14 years old, whereas Senior High School second graders were 17 years old. A total of 100 students enrolled from Junior High School and in Senior High School, and also a total of 100 students participated in the study. Care was taken that the number of students in each group, both types of schools, was the same and did not change during the study. Each group of students was determined by the appropriate symbol, a list of which is described in Table 1.

The test procedure

At the beginning of the tests, all the groups of students received appropriate teaching aid. One group of students preparing to perform experiments in the school chemistry laboratory used the first version of the program to simulate performing experiments (GKL, LKL). Similarly, the second group of students used the second version of the program (GKF, LKF), and the third group of students used the third version of the program (GKT, LKT). A fourth group of students was created to compare the performance of the students working with a program, using the Kinect interface to the results of students who have not worked with this program (GTF, LTF). Therefore, the fourth group of students worked only with the instructions and films without having access to the virtual laboratory. Before starting the test, all the groups of students had to solve the pretest to lay down their current knowledge level of the material about inorganic acids. Then, each group of students started working with the proper versions of the assigned teaching aids, according to their weekly chemistry timetable. The students representing different groups had prepared at home, using the program simulating chemical experiments or getting familiar with the text instructions and the instructional films on inorganic acids in order to perform these experiments in real terms in the school chemistry laboratory. The test lasted 5 weeks, during which all the groups of students simultaneously took part in 
it. After completing the planned experiments, the students were required to solve a posttest, the tasks of which were related to the experiments performed by them during the test. Three months after taking the posttest, the students were solving a delayed posttest. The delayed posttest contained the same multiple-choice tasks as the posttest, but arranged them in a different order, as well as the responses to these tasks. The pretest, the posttest and the delayed posttest consisted of 20 questions of choice. The test questions corresponded to the taxonomic categories of taxonomy educational objectives. To each taxonomy category of educational objectives were assigned five questions. The basis is B. Bloom's taxonomy of educational objectives (Bloom et al. 1956; Andreson and Krathwohl 2001), which is based on the classification of the educational goals, that enabled a precise and unambiguous description of the tested students capabilities. Czupial and Niemierko (1977), based on B. Bloom's taxonomy, developed a taxonomy of chemistry educational objectives. This taxonomy consists of two levels, the level of knowledge and the level of skills. The level of knowledge can be divided into two categories: remembering the information (A) and understanding the information (B). The skill level is also divided into two categories: the use of information in common situations (C) and the use of information in problem situations (D). The taxonomy level of knowledge can be divided into subcategories such as the knowledge of chemical terminology, which includes knowing chemical terms, facts, including the existence of elements and compounds, any qualitative and quantitative composition of chemical compounds. The skill level takes into account the student's use of information in situations known to him from school such as the ability to operate with chemical symbols, determining the formula of a chemical compound, entering the names of chemical compounds, chemical calculations, planning and the design of chemical experiments, formulating hypotheses. A diagnostic Likert scale survey was conducted (Likert 1932; Gamst et al. 2008), designed to examine the students' opinion about the method of using a virtual laboratory with the Kinect sensor as a way of preparing students for laboratory exercises in chemistry.

\section{The calculation methodology}

The basis for the calculation was the points obtained by the students in individual tests. They were multiple-choice tests, in which students could choose only one correct answer. Therefore, for every answer to a question, the students could receive 0 or 1 point. As the tests consisted of 20 questions, the maximum number of points obtained by the students was 20. Each group of students could receive a maximum of 500 points for each test. Therefore, in each test, which is the pretest, the posttest and the delayed test, for each category of the taxonomy educational objectives, every group of students could receive a maximum of 125 points. For the results obtained by the students in each test, an arithmetic mean was assigned for every group of students. In addition, a statistical modal was determined, stating which result was most frequently repeated in a group, and the variance specifying the variability of the results.

From the obtained test results, the increase in gained information by the students from the groups and the educational effectiveness of each version of the simulating chemistry laboratory program were calculated. Also, there was the durability of the information gained by the students representing different groups (Jagodzinski and Wolski 2012). Subsequently, the growth of information in different groups of students was calculated according to the following formula.

$\Delta W=\left[\left(E_{2}-E_{1}\right) / E_{1}\right] \cdot 100 \%$

Owhere $\Delta W$ the growth of information gained by students from the examined group, $E_{1}$ the sum of points obtained by the students from the examined group in the pretest and $E_{2}$ the sum of points obtained by the students from the examined group in the posttest.

Next, the effectiveness of the educational virtual laboratory with the reader (GKL, LKL) was determined, forming suitable pairs with the rest of the groups of students (Tables 4, 5). The calculations were made according to the following example for a pair of groups GKL-GKT.

$S=\left(\Delta W_{G K L}-\Delta W_{G K T}\right) / \Delta W_{G K T} \cdot 100 \%$

where $S$ the educational effectiveness of virtual laboratory's version with the teacher, $\Delta W_{G K L}$ the growth of information gained by the students from the GKL group and $\Delta W_{G K T}$ the growth of information gained by the students from the GKT group.

Also, the durability of the information gained by the students representing different groups was determined, based on the loss of their knowledge, which is expressed by the formula $\left[\left(E_{2}-E_{3}\right) / E_{2}\right] \cdot 100 \%$, and subtracting the resulting value from $100 \%$. The value of $100 \%$ is defined as the sum of the marks obtained by the students of each group in the final test.

$\Delta U=100 \%-\left[\left(E_{2}-E_{3}\right) / E_{2}\right] \cdot 100 \%$

where $\Delta U$ the durability of the information gained by the students representing different groups, $E_{2}$ the sum of the points obtained by the students from the examined group in the posttest and $E_{3}$ the sum of the points obtained by the students from the examined group in the delayed posttest.

The same procedure as above was applied to designate the increase in the gained information, educational efficiency and 
Table 2 The results of the pretest, posttest and delayed posttest expressed with the help of the arithmetic mean, the modal and the variance achieved by the Junior High School students

\begin{tabular}{|c|c|c|c|c|c|c|c|c|c|c|c|c|c|c|c|}
\hline \multirow[t]{2}{*}{ The name of the group } & \multicolumn{3}{|l|}{ A } & \multicolumn{3}{|l|}{$\mathrm{B}$} & \multicolumn{3}{|l|}{$\mathrm{C}$} & \multicolumn{3}{|l|}{$\mathrm{D}$} & \multicolumn{3}{|c|}{ G(generally) } \\
\hline & $\mathrm{T}_{\mathrm{pr}}$ & $\mathrm{T}_{\mathrm{po}}$ & $\mathrm{T}_{\mathrm{di}}$ & $\mathrm{T}_{\mathrm{pr}}$ & $\mathrm{T}_{\mathrm{po}}$ & $\mathrm{T}_{\mathrm{di}}$ & $\mathrm{T}_{\mathrm{pr}}$ & $\mathrm{T}_{\mathrm{po}}$ & $\mathrm{T}_{\mathrm{di}}$ & $\mathrm{T}_{\mathrm{pr}}$ & $\mathrm{T}_{\mathrm{po}}$ & $\mathrm{T}_{\mathrm{di}}$ & $\mathrm{T}_{\mathrm{pr}}$ & $\mathrm{T}_{\mathrm{po}}$ & $\mathrm{T}_{\mathrm{di}}$ \\
\hline \multicolumn{16}{|l|}{ GKL } \\
\hline Average $^{a}$ & 1,60 & 4,76 & 3,96 & 1,40 & 4,44 & 3,60 & 1,40 & 4,36 & 3,48 & 1,20 & 4,04 & 3,24 & 5,60 & 17,60 & 14,28 \\
\hline $\operatorname{Modal}^{\mathrm{b}}$ & 2,00 & 5,00 & 4,00 & 1,00 & 5,00 & 4,00 & 1,00 & 4,00 & 4,00 & 1,00 & 4,00 & 3,00 & 5,00 & 18,00 & 14,00 \\
\hline Variance $^{\mathrm{c}}$ & 0,50 & 0,19 & 0,62 & 0,42 & 0,67 & 1,00 & 0,25 & 0,41 & 0,76 & 0,75 & 0,54 & 0,77 & 2,67 & 1,83 & 8,71 \\
\hline \multicolumn{16}{|l|}{ GKF } \\
\hline Average & 1,64 & 4,60 & 3,56 & 1,48 & 4,16 & 3,12 & 1,32 & 3,80 & 2,76 & 1,28 & 3,36 & 2,56 & 5,72 & 15,92 & 12,00 \\
\hline Modal & 2,00 & 5,00 & 4,00 & 1,00 & 4,00 & 3,00 & 1,00 & 4,00 & 3,00 & 1,00 & 3,00 & 3,00 & 6,00 & 16,00 & 12,00 \\
\hline Variance & 0,41 & 0,33 & 0,76 & 1,01 & 0,31 & 0,86 & 0,29 & 0,75 & 0,77 & 0,29 & 0,66 & 0,76 & 1,54 & 2,66 & 4,00 \\
\hline \multicolumn{16}{|l|}{ GKT } \\
\hline Average & 1,72 & 4,72 & 3,36 & 1,40 & 3,84 & 2,92 & 1,28 & 3,52 & 2,52 & 1,08 & 3,16 & 2,36 & 5,48 & 15,24 & 11,16 \\
\hline Modal & 2,00 & 5,00 & 3,00 & 1,00 & 4,00 & 3,00 & 1,00 & 4,00 & 2,00 & 1,00 & 3,00 & 2,00 & 5,00 & 15,00 & 11,00 \\
\hline Variance & 0,38 & 0,29 & 1,16 & 0,33 & 0,89 & 0,74 & 0,21 & 0,51 & 1,01 & 0,08 & 0,47 & 0,91 & 1,09 & 2,94 & 4,47 \\
\hline \multicolumn{16}{|l|}{ GTF } \\
\hline Average & 1,64 & 4,44 & 3,08 & 1,40 & 3,64 & 2,60 & 1,28 & 3,56 & 2,32 & 1,12 & 3,00 & 2,04 & 5,44 & 14,64 & 10,04 \\
\hline Modal & 2,00 & 5,00 & 3,00 & 1,00 & 3,00 & 3,00 & 1,00 & 3,00 & 2,00 & 1,00 & 3,00 & 2,00 & 5,00 & 15,00 & 10,00 \\
\hline Variance & 0,41 & 0,51 & 0,83 & 0,42 & 0,91 & 0,75 & 0,46 & 0,92 & 0,73 & 0,36 & 1,17 & 0,71 & 1,92 & 3,07 & 2,79 \\
\hline
\end{tabular}

$T_{p r}$ The pretest, $T_{p o}$ the posttest, $T_{d i}$ the delayed posttest

a the arithmetic mean of the number of points obtained by the students in the different tests

b the most frequently repeated result in the collection

c a measure of the variability of the observed results

durability of the information, taking into account the different categories of taxonomic teaching purposes.

The results were statistically analyzed in order to determine the statistical significance of the differences. For this purpose, in the chi-square test, the confidence level was set at $p<0.05$.

\section{The test results}

Below, we present a summary table of the results of the research on Junior High School and Senior High School students.

The results of the pretest in the Junior High School (Table 2) indicate that the examined students showed an equal level of knowledge. The majority correctly answered two questions out of five, regarding category A the taxonomy of educational goals. However, in the case of category B, C and D taxonomy educational goals, most correctly answered one question out of five in each category. The Senior High School students (Table 3) during the pretest correctly answered two questions out of five in each category of the taxonomy of the educational goals.
The results of the final test in the Junior High School (Table 2) indicate that the students from the group GKL achieved better results in all the categories of the taxonomy goals of education than the students from the other groups. The observed differences in the results increased with the growth in the value of the taxonomy of the educational goals, with the largest differences in categories $\mathrm{C}$ and $\mathrm{D}$. The majority of students correctly answered five category A questions, the taxonomy of the educational goals. In category B of the taxonomy of the educational goals, the students from the group GKL mostly answered correctly, receiving the maximum number of marks, while the majority of the students from the GTF group correctly answered only three questions. In this category, the students from the groups GKF and GKT correctly answered four questions. In category $\mathrm{C}$ of the taxonomy of the educational goals, the same number of correct answers, which is four, was reported for the groups of students GKL, GKF and GKT. The students from the group GTF got the worst results in this category, because they mostly gave correct answers to three questions out of five. In the case of category $\mathrm{D}$ with the highest value of teaching, the best results obtained by the students from the GKL group were 
Table 3 The results of the pretest, posttest and delayed test expressed with the help of the arithmetic mean, modal and variance achieved by Senior High School students

\begin{tabular}{|c|c|c|c|c|c|c|c|c|c|c|c|c|c|c|c|}
\hline \multirow[t]{2}{*}{ Group name } & \multicolumn{3}{|l|}{ A } & \multicolumn{3}{|l|}{$\mathrm{B}$} & \multicolumn{3}{|l|}{$\mathrm{C}$} & \multicolumn{3}{|l|}{$\mathrm{D}$} & \multicolumn{3}{|c|}{ G(generally) } \\
\hline & $\mathrm{T}_{\mathrm{pr}}$ & $\mathrm{T}_{\mathrm{po}}$ & $\mathrm{T}_{\mathrm{di}}$ & $\mathrm{T}_{\mathrm{pr}}$ & $\mathrm{T}_{\mathrm{po}}$ & $\mathrm{T}_{\mathrm{di}}$ & $\mathrm{T}_{\mathrm{pr}}$ & $\mathrm{T}_{\mathrm{po}}$ & $\mathrm{T}_{\mathrm{di}}$ & $\mathrm{T}_{\mathrm{pr}}$ & $\mathrm{T}_{\mathrm{po}}$ & $\mathrm{T}_{\mathrm{di}}$ & $\mathrm{T}_{\mathrm{pr}}$ & $\mathrm{T}_{\mathrm{po}}$ & $\mathrm{T}_{\mathrm{di}}$ \\
\hline \multicolumn{16}{|l|}{ LKL } \\
\hline Average $^{a}$ & 2.12 & 4.80 & 4.04 & 2.04 & 4.72 & 3.88 & 1.96 & 4.44 & 3.64 & 1.92 & 4.28 & 3.44 & 8.04 & 18.24 & 15.00 \\
\hline Modal $^{\mathrm{b}}$ & 2.00 & 5.00 & 4.00 & 2.00 & 5.00 & 4.00 & 2.00 & 5.00 & 4.00 & 2.00 & 4.00 & 4.00 & 8.00 & 19.00 & 15.00 \\
\hline Variance $^{c}$ & 0.78 & 0.17 & 0.46 & 0.79 & 0.21 & 0.78 & 0.54 & 0.51 & 0.91 & 0.58 & 0.54 & 1.26 & 3.04 & 1.44 & 4.25 \\
\hline \multicolumn{16}{|l|}{ LKF } \\
\hline Average & 2.12 & 4.64 & 3.92 & 2.08 & 4.32 & 3.56 & 2.00 & 3.88 & 3.24 & 1.96 & 3.64 & 2.92 & 8.16 & 16.48 & 13.64 \\
\hline Modal & 2.00 & 5.00 & 4.00 & 2.00 & 4.00 & 4.00 & 2.00 & 4.00 & 3.00 & 2.00 & 4.00 & 3.00 & 8.00 & 16.00 & 13.00 \\
\hline Variance & 0.61 & 0.32 & 1.24 & 0.74 & 0.39 & 0.84 & 0.58 & 0.61 & 0.52 & 0.71 & 1.16 & 0.74 & 0.71 & 3.18 & 3.41 \\
\hline \multicolumn{16}{|l|}{ LKT } \\
\hline Average & 2.08 & 4.64 & 3.64 & 2.04 & 4.36 & 3.36 & 1.96 & 3.80 & 2.92 & 1.84 & 3.48 & 2.44 & 7.92 & 16.28 & 12.36 \\
\hline Modal & 2.00 & 5.00 & 4.00 & 2.00 & 4.00 & 3.00 & 2.00 & 4.00 & 3.00 & 2.00 & 4.00 & 2.00 & 8.00 & 17.00 & 12.00 \\
\hline Variance & 0.58 & 0.32 & 1.16 & 1.04 & 0.57 & 0.74 & 0.54 & 1.08 & 0.74 & 0.64 & 0.84 & 1.17 & 2.58 & 2.54 & 4.66 \\
\hline \multicolumn{16}{|l|}{ LTF } \\
\hline Average & 2.04 & 4.60 & 3.48 & 2.08 & 4.04 & 3.20 & 2.04 & 3.68 & 2.60 & 1.92 & 3.44 & 2.36 & 8.08 & 15.76 & 11.64 \\
\hline Modal & 2.00 & 5.00 & 4.00 & 2.00 & 4.00 & 3.00 & 2.00 & 4.00 & 3.00 & 2.00 & 3.00 & 2.00 & 8.00 & 16.00 & 12.00 \\
\hline Variance & 0.62 & 0.33 & 1.01 & 0.74 & 0.71 & 0.75 & 0.96 & 0.98 & 1.00 & 0.66 & 0.84 & 1.41 & 1.83 & 3.61 & 6.57 \\
\hline
\end{tabular}

$T_{p r}$ the pretest, $T_{p o}$ the posttest, $T_{d i}$ the delayed posttest

a the arithmetic mean of the number of points obtained by the students in the different tests

b the most frequently repeated result in the collection

$c$ the measure of the variability of the observed results

from answering four out of five questions. The students from the other groups obtained similar results answering three questions.

In the case of the High School students (Table 3), the best performance in all the categories of the educational goals $\mathrm{A}, \mathrm{B}, \mathrm{C}$ and $\mathrm{D}$ was obtained by the LKL group, while all the other groups of students achieved worse results, but were close to each other. At the same time, most of the students correctly answered the maximum number of questions on category A taxonomy educational goals. In category $\mathrm{B}$ and category $\mathrm{C}$ of the educational goals, the majority of the students from the LKL group answered five questions correctly. The other groups of students in categories $\mathrm{B}$ and $\mathrm{C}$ answered four out of five questions correctly. In category $\mathrm{D}$, the students mostly answered four out of five questions properly, with the exception of the students representing the LTF group, who correctly answered three out of five questions.

The test results of the delayed test in Junior High School (Table 2) indicate that within category A of the educational goals, the students from the groups GKL and GKF correctly answered four out of five questions correctly, while the students from the groups GKT and GTF came out worse and correctly answered only three questions. Within category B of the educational goals, only the students from the GKL group correctly answered four questions, while the majority of the students from the other groups achieved the same results, answering only three questions. In category $\mathrm{C}$, the best results were achieved by the students from the GKL group, correctly answering four questions. In this category, the GKF group of students answered three questions, and the students from the groups GKT and GTF gave correct answers to only two questions. In category D, regarding the skills of problem solving, both the GKL and GKF students achieved the same results by providing correct answers to three questions. Likewise the GKL and GKF students gave correct answers to two questions.

The results of the delayed posttest conducted with the Senior High School students (Table 3) are better than the adequate results of the Junior High School students and are more even. In category A of the educational goals, the students from the LKL, LKF, LKT and LTF groups have obtained the same results answering four questions properly. In category $\mathrm{B}$, the LKL and LKF students again received a high score, correctly answering four questions, whereas the LKT and LTF students answered three questions averagely. The LKL students also received a high score by correctly answering four questions on average. In 
these category groups, the LKF group gave correct answers to three questions, while the groups LKT and LTF gave correct answers to three and two questions, respectively.

After solving the final test, the groups GKL, GKF, GKT and LKL, LKF, LKT answered the diagnostic survey questions. The results of this survey are presented in Table 6.

\section{The interpretation of the test results}

The results of the pretest carried out in the Junior High School (Table 4) indicate that the examined students showed a very similar, low level of knowledge of the subject of chemical acids, which the research had included. In contrast, the pretest results in the Senior High School (Table 5) are $45 \%$ higher, because the Senior High School students have a larger body of knowledge and more skills acquired while studying chemistry in the Junior High School. Almost the same level of information in the Junior High School groups and almost the same level of information in the Senior High School groups indicate that the groups were matched correctly and were able to participate in further studies.

Analyzing the results of the posttest of Junior High School students (Table 4) can show that the group GKL achieved the best results. The students in this group, while doing virtual experiments, performed the next commands from the reader. It can, therefore, be concluded that this version of the laboratory suited most students, because today's media is dominated by the manner of communication through image and sound commentary, to which students are accustomed.

Analyzing the performance of the GKF group, the students who, by virtual experiments, benefited from the instructions on the film, we can conclude that they are about $11 \%$ worse than in the case of the GKL group of students. Removing the reader's commands, which allow you to perform laboratory activities in the correct order at any pace (singular information) and replacing it with multimedia content in the form of a film in which these activities are given as a continuity and with a predetermined pace (an accumulation of information), resulted in a decrease in the efficiency of the education by $18 \%$ (Table 4). The results of the GKT group of students in the final test are almost identical to the results of the GKF group. You can see that the replacement of the instructional film with the instructions in the form of a text viewed on a screen gave similar results. This is due to the fact that the text instructions as well as the film instructions give important information-commands in a concise, cumulative way. The GTF group of students, working with the text instructions and a film, but without the virtual laboratory,
Table 4 A summary of the results of the gain of the knowledge, the effectiveness of the examined teaching aid and the durability of the knowledge, achieved by the groups of Junior High School students, working with the examined teaching aid

The taxonomic categories of the educational goals

\begin{tabular}{lccccc}
\hline & A & B & C & D & G(generally) \\
\hline Group symbol & \multicolumn{5}{c}{ Increase in a student's } \\
GKL & 198 & 217 & 211 & 237 & 214 \\
GKF & 180 & 181 & 188 & 163 & 178 \\
GKT & 174 & 174 & 175 & 193 & 178 \\
GTF & 171 & 160 & 178 & 168 & 169 \\
Educational effectiveness of each pair [\%] & & \\
GKL-GKF & $7 *$ & $13 *$ & 19 & 37 & 18 \\
GKL-GKT & $5 *$ & 25 & 32 & 37 & 23 \\
GKL-GTF & $13 *$ & 36 & 30 & 51 & 30 \\
The durability of the knowledge gained by the students [\%] \\
GKL & 83 & 81 & 80 & 80 & 81 \\
GKF & 77 & 75 & 73 & 76 & 75 \\
GKT & 71 & 76 & 72 & 75 & 73 \\
GTF & 69 & 71 & 65 & 68 & 69
\end{tabular}

The sign $(*)$ indicates statistically insignificant results, determined from the chi-square test

Table 5 A summary of the results of the gain of the knowledge, the effectiveness of the examined teaching aid and the durability of the knowledge, achieved by groups of Senior High School students, working with the examined teaching aid

\begin{tabular}{|c|c|c|c|c|c|}
\hline \multicolumn{6}{|c|}{ The taxonomic categories of the educational goals } \\
\hline & A & $\mathrm{B}$ & $\mathrm{C}$ & $\mathrm{D}$ & G(generally) \\
\hline Group symbol & \multicolumn{5}{|c|}{ Increase in a student's knowledge [\%] } \\
\hline LKL & 126 & 131 & 127 & 123 & 127 \\
\hline LKF & 119 & 108 & 94 & 86 & 102 \\
\hline LKT & 123 & 114 & 94 & 89 & 106 \\
\hline LTF & 125 & 94 & 80 & 79 & 95 \\
\hline \multicolumn{6}{|c|}{ Educational effectiveness of each pair [\%] } \\
\hline LKL-LKF & $6^{*}$ & 22 & 35 & 43 & 24 \\
\hline LKL-LKT & $3 *$ & $16^{*}$ & 35 & 38 & 20 \\
\hline LKL-LTF & $1 *$ & 39 & 57 & 55 & 33 \\
\hline \multicolumn{6}{|c|}{ The durability of the knowledge gained by the students [\%] } \\
\hline LKL & 84 & 82 & 82 & 80 & 82 \\
\hline LKF & 84 & 82 & 84 & 80 & 83 \\
\hline LKT & 78 & 77 & 77 & 70 & 76 \\
\hline LTF & 76 & 79 & 71 & 69 & 74 \\
\hline
\end{tabular}

The sign $(*)$ indicates statistically insignificant results, determined from the chi-square test

achieved the worst results. Ridding the students of the chance of simulating laboratory exercises resulted in a less engaged attitude of the students in the experimental work, which gave inferior results. Considering the results 
obtained in terms of the goals of education, it can be seen that the GKL group of students achieved similar, high scores in all the four categories of taxonomy educational goals. The other groups of students, that is, GKF, GKT and GTF, achieved similar results in the category A taxonomy of the educational goals.

The teaching aids used in the research had no significant effect with the extent of differentiations in memorizing information through the Junior High School students. This is indicated by the results of the effectiveness of the examined teaching aid for category A of the taxonomy educational goals, and these differences are not statistically significant (Table 4). In terms of understanding the information which refers to category $\mathrm{B}$ of the taxonomy, the differences in the effectiveness are noticed only among the GKL-GKT and GKL-GTF groups of students. Interrupting the experiment to read the fragment has a negative impact on the understanding of information as well as a lack of a simulation when performing the experiment. For students from the GKF group, this difference is so small that it is statistically insignificant. In the case of categories $\mathrm{C}$ and $\mathrm{D}$ on laboratory problem-solving skill tasks, the GKL group of students came off the best compared with the other groups of students. This is beneficial, especially that these two categories classified as a skill level have the highest educational value. Here you can see the reader's positive impact on the students, acting as a virtual instructor.

In the case of the research conducted in the Junior High School on the stability of knowledge, it can be seen that it is the highest in the GKL group of students. In the other groups, the durability of the knowledge is at a lower level. Also, in this case, the use of a virtual laboratory, where the students were instructed by the reader, turned out to be the best combination.

The consequence of the applied calculation methodology of the growth of the knowledge is the high increment of the gain achieved, especially by the Junior High School students. The reason is that the results of the pretest are the basis for the growth of the knowledge (formula 1).

Chemistry in Junior High Schools is a new subject and chemistry issues are also brand new for Junior High School students. For this reason, the Junior High School students achieved the worse results in the pretest. The situation is different in the case of the Senior High School students. These students are continuing their chemistry education, expanding their knowledge gained earlier in the Junior High Schools and, therefore, performing better in the pretest than the Junior High School students. For this reason, the results of the growth of information are particularly high in the case of the Junior High School students with the assumed methodology of calculation. In the case of the Senior High School students, when analyzing the test results (Table 5) of particular groups, we can conclude that the best results of the posttest were achieved by the LKL group of students. The LKF and LKT students got similar results to each other, but lower by about $11 \%$ than the LKL group of students. The worst results were achieved by the LTF group of students. Comparing the results of all the Senior High School groups, it can be seen that also in this case the effectiveness of education is influenced by the media's way of transmitting messages. Examining the students' performance in terms of different categories of taxonomy educational goals, it can be seen that the way of transmitting information has no significant effect on retaining the information, because all the students of the examined groups in category A of taxonomy educational goals got similar results. This is reflected in the calculated effectiveness of the teaching aids used, because, in category A, the differences in the performance are not statistically significant. In category B only, the LTF group of students achieved the worst result, which was caused by their inability to simulate the chemical experiments. On this basis, it can be concluded that practical activity has a significant impact on the understanding of the information (Table 5). The tasks of the posttest, relating to the other two categories, C and D, of the taxonomy educational goals, the LKL group of students got the best results. The remaining groups achieved significantly worse results in the pretest where the LKF and LKT students got similar results. The LTF group got the poorest results, which is reflected by the calculated educational effectiveness of various teaching aids in these taxonomy categories.

Analyzing the results of the delayed posttest that was conducted among the Senior High School students, indicating the degree of the stability of the information, it can be seen that the LKL and LKF students got very similar results in the range of $82-83 \%$. This confirms the thesis described here earlier, this thesis proves that students nowadays primarily use visualized information, in which picture and sound are dominant. Therefore, the LKT group of students, who did not use the commands of a reader and the help of the instructional film, showed a lower retention of the information. In contrast, the lack of manual involvement by the LTF group, who did not work with the virtual laboratory, results in that they achieved a worse performance in the sustainability of the information when compared with the LKL and LKF groups, which had at their disposal a virtual laboratory with a reader or an instructional film. The results of the diagnostic survey (Table 6) confirm the usefulness of a virtual chemistry laboratory that uses the Kinect sensor for chemistry education. The students representing the examined groups, working with a virtual laboratory, confirmed that this has increased their commitment to work in a real laboratory. In the majority of the surveyed students, this has increased the willingness to work in a school laboratory. The students 
Table 6 The results of the diagnostic survey

\begin{tabular}{|c|c|c|c|c|c|c|c|c|c|c|}
\hline \multirow[t]{3}{*}{ Questions } & \multicolumn{10}{|c|}{ Answers [\%] } \\
\hline & \multicolumn{2}{|c|}{$1 *$} & \multicolumn{2}{|l|}{$2^{*}$} & \multicolumn{2}{|l|}{$3 *$} & \multicolumn{2}{|l|}{$4^{*}$} & \multicolumn{2}{|l|}{$5^{*}$} \\
\hline & $\mathrm{G}$ & $\mathrm{L}$ & G & $\mathrm{L}$ & G & $\mathrm{L}$ & G & $\mathrm{L}$ & G & $\mathrm{L}$ \\
\hline $\begin{array}{l}\text { 1. Does your work in a virtual laboratory increase your commitment to the work in a real } \\
\text { laboratory? }\end{array}$ & 0 & 0 & 0 & 0 & 3 & 7 & 19 & 15 & 79 & 79 \\
\hline $\begin{array}{l}\text { 2. Are you more willing to work in a real laboratory when having exercised performing } \\
\text { experiments in a virtual laboratory before? }\end{array}$ & 0 & 0 & 3 & 3 & 5 & 8 & 23 & 31 & 70 & 59 \\
\hline $\begin{array}{l}\text { 3. Does your work in a virtual laboratory contribute to an increase in the efficiency of your work } \\
\text { in a real laboratory by shortening the time required to perform the experiments? }\end{array}$ & 0 & 0 & 0 & 0 & 7 & 15 & 12 & 19 & 81 & 67 \\
\hline $\begin{array}{l}\text { 4. Does your work in a virtual laboratory contribute to an increase in the efficiency of your work } \\
\text { in a real laboratory by reducing the number of errors while performing experiments? }\end{array}$ & 3 & 4 & 1 & 3 & 0 & 3 & 28 & 33 & 68 & 58 \\
\hline $\begin{array}{l}\text { 5. Did your achievements in a virtual laboratory encourage you to verify them in a real } \\
\text { laboratory? }\end{array}$ & 0 & 0 & 0 & 0 & 1 & 7 & 35 & 47 & 64 & 47 \\
\hline $\begin{array}{l}\text { 6. Did your work in a virtual laboratory make you want to do more experiments in a real } \\
\text { laboratory than the school schedule provides? }\end{array}$ & 3 & 9 & 0 & 1 & 7 & 11 & 29 & 36 & 62 & 43 \\
\hline $\begin{array}{l}\text { 7. Thanks to the work in the virtual laboratory, can you easily design new chemical } \\
\text { experiments? }\end{array}$ & 7 & 11 & 12 & 15 & 11 & 15 & 37 & 41 & 33 & 19 \\
\hline $\begin{array}{l}\text { 8. Has your work in a virtual laboratory made you more confident in performing laboratory } \\
\text { activities in a real laboratory? }\end{array}$ & 0 & 0 & 0 & 0 & 3 & 8 & 13 & 21 & 84 & 71 \\
\hline $\begin{array}{l}\text { 9. Has your work in a virtual laboratory strengthened your belief that you are able to perform } \\
\text { experiments with positive results in a real laboratory? }\end{array}$ & 0 & 0 & 1 & 3 & 13 & 19 & 31 & 38 & 55 & 41 \\
\hline $\begin{array}{l}\text { 10. Has your work in a virtual laboratory increased your belief in the effectiveness of manual } \\
\text { task related work in a real laboratory? }\end{array}$ & 0 & 0 & 4 & 5 & 12 & 17 & 29 & 35 & 55 & 43 \\
\hline
\end{tabular}

* Answers-1. Strongly disagree, 2. Disagree, 3. Neither agree nor disagree, 4. Agree, 5. Strongly agree; G-Junior High School, L-Senior High School

also felt that the efficiency of their work had increased, because they could carry out experiments in a shorter time committing less error.

The positive results of the experiments, which were obtained by the students while working with a virtual laboratory, encouraged those students to repeat them in the real laboratory and to perform additional experiments, doing more than those that were required. Thanks to the work with the virtual laboratory, the student's ability to solve laboratory problems and design new laboratory experiments increased. This opinion of the students is confirmed by the results obtained from them in the category D of the taxonomy educational goals. The results of the survey also indicate that the students have mastered laboratory activities, which increased their belief that they can now perform more experiments with positive results. The students emphasized that training with a virtual laboratory increased their sense of effectiveness with regard to their work in a real laboratory.

\section{Summing up}

Based on the results of the research presented above, a conclusion can be drawn that the use of Natural User Interface, which is Kinect along with appropriate software, gives good results in terms of teaching chemistry when using the virtual laboratory. The students work in the virtual laboratory actually helps to increase their engagement while working in a real laboratory. The increase in this activity and the benefits of working in a laboratory were examined by Hofstein and Lunetta (1982). The additional use of the Kinect sensor, which allows the students to perform natural gestures and movements, just like in a real laboratory, creates an even higher growth in their activity. The use of a virtual laboratory in conjunction with the Kinect sensor allows you to perform chemical experiments that bear the basic information for the students.

Tatli (2009) examined the impact of the students' work in the school laboratory for the individualization of their actions, thanks to which each student can separately train basic skills. In our case, before students begin work in a real laboratory, they can train on their ability to perform the experiments outside the classroom, for example, at home, which increases the individualization of work. This is possible thanks to our virtual laboratory, which allows students to work wherever the technical conditions allow it. We have observed, just like Odubunni and Balagun (1991) and Ayas et al. (1994), that working in a school laboratory increases problem-solving skills by the students, especially in terms of categories $\mathrm{C}$ and $\mathrm{D}$ of the taxonomy learning 
goals, which is confirmed by the results of our research. In addition, the growth of these skills can be enhanced by training on the ability to work in a laboratory by exercising before in a virtual laboratory. In the end, it contributes to an increase in the gained information by students and the retention of the knowledge, especially in terms of categories $\mathrm{C}$ and $\mathrm{D}$ in taxonomy learning goals.

The use of a virtual laboratory with the Kinect sensor creates among students a higher commitment to the work in the laboratory. The achieved results are consistent with the research results (Roschelle et al. 2000; Calik and Coll 2012; Calik et al. 2013). As Zhang (2013) noticed, an important issue is the proper integration and implementation of ICT technology in the educational process. In the case of a virtual laboratory with Kinect sensor technology, the implementation of NUI assists in teaching chemistry is especially successful being conducting chemical experiments. Based on this research, it can be concluded that the use of innovative technologies (Calik 2013; Ebenezer et al. 2011, 2012; Xie and Reider 2013), an example of which is NUI, is justified by bringing positive results in teaching. The virtual chemical laboratory with the Kinect sensor is an educational program, but may as well serve as a Serious Game.

Our research results are consistent with the opinion of (De Grove et al. 2012) and indicate that the advantage of a virtual laboratory Kinect is the ability to work effectively with it, for example, at home, in order to prepare in the range of laboratory work for new lessons. In this case, the individualization of activities, consisting mainly of adjusting the pace of work to the personal learning capacities of the student, is possible (Stieff and Wilensky 2003; Pekdag 2010).

With the virtual laboratory using Kinect, the realism of the simulation experiments significantly increased, causing willingness to work with them among students. They emphasized the ability to perform manual tasks almost the same as when working in a real laboratory. Among most of the available programs that allow the simulation of experiments and chemical processes, the mouse and the keyboard are used for control. In the case of our program, neither the mouse nor the keyboard is used, with control being carried out by means of gestures and hand movements. Students, while performing virtual experiments, were involved emotionally in the same way as they are while playing computer games, in which the user's emotional involvement is high (Khan 2007). As you can see, NUI provide an opportunity for the practical use of them inter alia in the remote method of education, the "Flipped Classroom" method of education ("Flipped classrooms" 2012) and the IBSE method of teaching, involving an independent creation of conclusions on the basis of practical action ("Science Education NOW" 2007).
In conclusion, the virtual chemistry laboratory using Kinect has a positive effect on the involvement of the students and causes them to increase their self-efficacy while working in a real laboratory. This is due to the fact that the students have direct and frequent contact with the media, in which the dominant role is played by picture and sound. The ongoing further technological development of Natural User Interfaces (NUI) will allow an even more accurate reflection of the laboratory work in a virtual environment.

Open Access This article is distributed under the terms of the Creative Commons Attribution License which permits any use, distribution, and reproduction in any medium, provided the original author(s) and the source are credited.

\section{References}

Andreson LW, Krathwohl DR (2001) A Taxonomy for Learning, Teaching and Assessing: a Revision of Bloom's Taxonomy. Longman Publishing, New York

Atwater MM (2000) Equity for Black Americans in precollege science. Sci Educ 84:154-179

Ayas A, Cepni S, Akdeniz AR (1994) Importance of laboratory in science education-II. Contemp Educ J 205:7-11

Bernard RM, Abrami PC, Lou Y, Borokhovski E, Wade A, Wozney L (2004) How does distance education compare with classroom instruction? A meta-analysis of the empirical literature. Rev Educ Res 74:379-439

Bílek M (2010) Natural science education in the time of virtual worlds. J Balt Sci Educ 9(1):4-5

Bloom BS, Engelhart MD, Furst EJ, Hill WH, Kratwohl DR (1956) Taxonomy of educational objectives; the classification of educational goals. In: Handbook 1: cognitive domain. David McKay, New York

Bozdogan AE, Yalcin N (2004) The rate of experiments being carried out in science lessons at elementary education and the problems encountered during the physics experiments. J Kirsehir Educat Fac 5:59-70

Calik M (2013) Effect of technology-embedded scientific inquiry on senior science student teachers' self-efficacy. Eurasia J Math Sci Technol Educ 9(3):223-232

Calik M, Coll RK (2012) Investigating socioscientific issues via scientific habits of mind: development and validation of the scientific habits of mind survey (SHOMS). Int J Sci Educ 34(12):1909-1930

Calik M, Turan B, Coll RK (2013) A cross-age study of elementary student teachers' scientific habits of mind concerning socioscientific issues. Int J Sci Math Educ. doi:10.1007/s10763-0139458-0

Chee YS, Tan CD (2012) Becoming Chemists through Game-based inquiry learning: the case of legends of Alkhimia. Electron $\mathrm{J}$ e-Learn 10(2):185-198

Chemistry Labs (n.d.) Retrieved 11 March 2014 from http:// onlinelabs.in/chemistry

Cobb P, Bowers J (1999) Cognitive and situated learning perspectives in theory and practice. Educ Res 28(2):4-15

Controls for Wii (n.d.) Retrieved 11 March 2014 from http://www. nintendo.com/wii/what-is-wii/\#/controls

Czupiał K, Niemierko B (1977) Methodology of chemical test. WSiP Warszawa 
De Grove F, Van Looy J, Neys J, Jansz J (2012) Playing in school or at home. An exploration of the effects of context on educational game experience. Electron J e-Learn 10(2):185-198

Dede CJ, Salzman M, Loftin RB (1996) The development of a virtual world for learning new Newtonian mechanics on high school students. Multimedia, hypermedia and virtual reality: models, systems, and applications, vol 1077. Springer-Verlag, Berlin, pp 87-106

Ebenezer JV, Kaya ON, Ebenezer DL (2011) Engaging students in environmental research projects: perceptions of fluency with innovative technologies and levels of scientific inquiry abilities. J Res Sci Teach 48(1):94-116

Ebenezer J, Columbus R, Kaya ON, Zhang L, Ebenezer DL (2012) One science teacher's professional development experience: a case study exploring changes in students' perceptions on their fluency with innovative technologies. J Sci Educ Technol 21(1):22-37

Edelson DC (1998) Realizing authentic science learning through the adaptation of scientific practice. In: Fraser BJ, Tobin KG (eds) International handbook of science education. Kluwer Academic, Dordrecht, pp 317-332

Flipped classrooms (2012) Retrieved 11 March 2014 from http://net. educause.edu/ir/library/pdf/ELI7081.pdf

Gamst G, Meyers LS, Guarino AJ (2008) Analysis of variance designs. Cambridge University Press, New York, A Conceptual and Computational Approach with SPSS and SAS, p 10

Hofstein A, Lunetta VN (1982) The role of the laboratory in science teaching neglected aspects of research. Rev Educ Res 52: 201-217

Jagodziński P, Wolski R (2012) Assessing the educational effectiveness of film of chemical experiments for educating deaf-mute junior high and high school students. J Chem Educ 89: 1122-1127. doi:10.1021/ed101052w

Khan MK (2007) Emotional and Behavioral Effects of Video Games and Internet Overuse, Report of the council on science and public health, Retrieved 11 March 2014 from http://www.amaassn.org/resources/doc/csaph/csaph12a07-fulltext.pdf

Kinect for Windows (n.d.) Retrieved 11 March 2014 from http:// research.microsoft.com/en-us/collaboration/focus/nui/kinect-win dows.aspx

Kosner AW (2012) Leap Motion's High-Resolution Natural User Interface Will Make Today's Touch A 'Legacy', Forbes, Retrieved 11 March 2014 from http://www.forbes.com/sites/ anthonykosner/2012/07/16/leap-motions-high-resolution-naturaluser-interface-will-make-todays-touch-a-legacy/

Krajcik JS (2002) The value and challenges of using learning technologies to support students in learning science. Res Sci Educ 32:411-414

Krajcik JS, Blumenfeld PC, Marx RW, Soloway E (2000) Instructional, curricular and technological supports for inquiry in science classrooms. In: Minstrill J, van Zee EH (eds) Inquiring into inquiry learning and teaching in science. American Association for the Advancement of Science, Washington, DC, pp 283-315

Lagowski JJ (1998) Chemical education: past, present, and future. J Chem Educ 75(4):425-436

LEAP Motion (n.d.) Retrieved 11 March 2014 from https://www. leapmotion.com/product

Leite L, Afons AS (2002) Prospective physical sciences teachers' use of laboratory activities: an analysis of its evolution due to a science teaching methods course. Rev Elect Enseñ Ciencias 1:153-179

Likert R (1932) A Technique for the Measurement of Attitudes. Arch Psychol 140:55

Linn M (2003) Technology and science education: starting points, research programs, and trends. Int J Sci Educ 25(6):727-758
Millar R (2004) The role of practical work in the teaching and learning science. Role and Vision. National Academy of Science, Washington DC, High School Science Laboratories

Murphy S (2012) Design Considerations for a Natural User Interface (NUI), Texas Instruments Incorporated, Dallas, TX, Retrieved 11 March 2014 from http://www.ti.com/lit/wp/spry181/spry181.pdf

Natural User Interface (NUI) (2011) Retrieved 11 March 2014 from http://whatis.techtarget.com/definition/natural-user-interface-NUI

Odubunni T, Balagun A (1991) The effect of laboratory and lecture teaching methods on cognitive achivement in integrated science. J Res Sci Teach 28:213-224

Pekdag B (2010) Chemistry learning alternative routes: animation, simulation, video, multimedia. J Turkish Sci Educ 7:79-110

Roschelle JM, Pea RD, Hoadley CM, Gordin DN, Means BM (2000) Changing how and what children learn in school with computerbased technologies. Future Child Child Comput Technol 10(2): 76-101

Roth WM, Roychoudhury A (1993) The development of science process skills in authentic contexts. J Res Sci Teach 30:127-152

Sánchez J, Olivares R (2011) Problem solving and collaboration using mobile serious games. Comput Educ 57:1943-1952

Sanger MJ (2000) Addressing student misconceptions concerning electron flow in aqueous solutions with instruction including computer animations and conceptual change strategies. Int J Sci 22:521-537

Science Education NOW (2007) A renewed pedagogy for the future of Europe. European Communities. Retrieved 11 March 2014 from http://ec.europa.eu/research/science-society/document_ library/pdf_06/report-rocard-on-science-education_en.pdf

Skeletal Tracking (n.d.) Retrieved 11 March 2014 from http://msdn. microsoft.com/en-us/library/hh973074.aspx

Stieff M, Wilensky U (2003) Connected chemistry-incorporating interactive simulations into the chemistry classroom. J Sci Educ Technol 12(3):285-302

Svec MT, Anderson H (1995) Effect of microcomputer based laboratory on students graphing interpretation skills and conceptual understanding of motion. Dissertation Abstract International 55(8):23-38, New York

Tamir P, Lunetta VN (1981) Inquiry-related tasks in high school science laboratory handbooks. Sci Educ 65(5):477-484

Tatli ZH (2009) Computer based education: online learning and teaching facilities. Energy Educ Sci Technol Part B 1:171-181

Tatli Z, Ayas A (2012) Becoming Chemists through game-based inquiry learning: the case of legends of Alkhimia. Electron $\mathrm{J}$ e-Learn 10(2): 185-198

Tezcan H, Bilgin E (2004) Affects of laboratory method and other factors on the student success in the teaching of the solvation subject at the high schools. J Gazi Educ Fac 24:175-191

This Is How I Move (n.d.) Retrieved 11 March 2014 from http://us. playstation.com/ps3/playstation-move/

Windows Presentation Foundation (n.d.) Retrieved 11 March 2014 from http://msdn.microsoft.com/pl-pl/library/ms754130.aspx

XAML Overview (n.d.) Retrieved 11 March 2014 from http://msdn. microsoft.com/pl-pl/library/ms752059.aspx

Xie Y, Reider D (2013) Integration of innovative technologies for enhancing students' motivation for science learning and career. J Sci Educ Technol. doi:10.1007/s10956-013-9469-1

Yang KY, Heh JS (2007) The impact of internet virtual physics laboratory instruction on the achievement in physics, science process skills and computer attitudes of 10th grade students. J Sci Educ Technol 16:451-461

Zhang L (2013) A meta-analysis method to advance design of technology-based learning tool: combining qualitative and quantitative research to understand learning in relation to different technology features. J Sci Educ Technol. doi:10.1007/ s10956-013-9460-x 